\title{
On Liquid Metal Wetting of Casting Rings for DC Casting
}

\author{
N. Bayat, T. Carlberg \\ Department of Natural Sciences, Mid Sweden University, 85170 Sundsvall, Sweden
}

Keywords: wettability, direct chill (DC) casting, vertical drags (VD), contact angle, sessile drop.

\begin{abstract}
During air-slip direct chill casting of aluminum alloys, uneven or low air pressure areas at the surface of the porous graphite ring mold, can cause the metal to stick to the graphite ring and produce traces along the billets called vertical drags (VD). To prevent this type of defect, it would be an advantage to decrease the wettability of the graphite ring. It has been shown that nanostructured surfaces can have hydrophobic properties, and a question is whether the same effect can be achieved for molten metals. $\mathrm{A} \mathrm{TiO}_{2}$ nanowire structure is proposed to cover the casting ring, and the wetting behavior of such a structure has been studied, and compared to the wetting at a regular graphite ring surface by the dispensed sessile drop method. The results showed that the nanostructured surface very strongly de-wets metal droplets.
\end{abstract}

\section{Introduction}

Wettability measurements can be defined by contact angle measurements between solid and liquid interface, which is obtained by the tangent line from the contact point of liquid vapor interface. The wettability is calculated by the value of the contact angle which is related to the interfacial energy of the solid, liquid and vapor $[1,2]$. When the contact angle is $<<90^{\circ}$ then the wettability is very high and while contact angle is $>>90^{\circ}$ then the wettability is very low [2-4].

The investigation of wetting behavior at elevated temperature is one the essential requirements for metallurgy casting and foundry industry and the characteristics of interfaces between a molten metal and a solid play an important role in selecting suitable materials or processing parameters $[5,6]$. In some applications the good wettability of the solid by the liquid is preferred, in others it is necessary to prevent the interaction of solid and liquid [7].

There are different types of wettability measurements e.g. sessile drop, maximum bubble pressure, drop weight, tilted plate method etc. [8].

In some cases (e.g. molten aluminum), at the elevated temperatures, due to the changes of the contact angle, it is essential to prevent the oxidization of aluminum droplet [9]. It is reported [8] that a layer of aluminum oxide on the surface of molten aluminum can increase the contact angle by several tens of degrees and hence the wettability is reduced.

Wettability of solid by liquid and their interactions at an interface, determine the feasibility and the final quality of products from processes such as soldering and MMC production [10]. Also the quality of aluminum billets which are produced by DC casting can be influenced by the wettability by molten aluminum on the graphite in the casting mold, however, in this case minimum wetting is desired. Studying the wetting behavior of a graphite ring, used in DC casting of aluminum alloys, is crucial for the aluminum industry. Defects such as vertical drags can be initiated by the interaction and sticking of the molten aluminum to the graphite ring [11]. Initiations of such defects are related to the interaction of the graphite ring with aluminum and aluminum alloys.

In this study the contact angles between graphite ring and molten aluminum are measured at different temperatures to characterize the wettability of the graphite ring. Due to high reactivity of aluminum with oxygen, it is not possible to measure the contact angle of graphite by molten aluminum by conventional contact angle measurement methods. Hence, sessile drop method in high vacuum condition needs to be used to measure the wetting characteristics.

As some 1D nanostructured surfaces have been shown to have very poor wettability during interaction with liquids at room temperature $[12,13]$, it would be interesting to study whether such a structure can be used to decrease the wettability during interaction also with liquid metals. Such a surface could possibly replace or cover the graphite ring to prevent the formation of vertical drag defects on billets. Therefore $\mathrm{TiO}_{2}$ nanowires were produced on a $\mathrm{Ti}$ substrate to obtain a nanostructure surface. The wettability of that surface was then compared to the wettability behavior of a graphite ring.

\section{Experimental procedure}

To produce $\mathrm{TiO}_{2}$ nanowires, the pure titanium substrate with the dimension of $5 \times 5 \mathrm{~mm}^{2}$ and the thickness of $1 \mathrm{~mm}$, was used. The titanium substrate was boiled in $\mathrm{HCl}$ for $20 \mathrm{~min}$ to remove the surface oxide layer. Then $30 \mathrm{~nm}$ of gold was deposited on the titanium substrate by sputtering. The substrates were then held in an $\mathrm{Ar}$ atmosphere at a pressure of $5 \mathrm{mbar}$, at $1000{ }^{\circ} \mathrm{C}$ for $4 \mathrm{~h}$, to produce $\mathrm{TiO}_{2}$ nanowires.

Contact angle measurements were done between pure molten aluminum $(99,99 \%$ aluminum) and graphite rings from DC casting molds and $\mathrm{TiO}_{2}$ nanowire structures. The method utilized was the dispensed sessile drop method in a high vacuum $\left(\approx 2 \times 10^{-4} \mathrm{~Pa}\right)$, where a droplet of $3 \mathrm{~mm}$ diameter of molten aluminum was placed on the mentioned substrates. The same technique and equipment as in [10] was used.

The experiments started at $800^{\circ} \mathrm{C}$ and then the molten aluminum droplets were cooled down to $650^{\circ} \mathrm{C}$. The molten droplets were then kept at each temperature (with $10^{\circ} \mathrm{C}$ changes), for $30 \mathrm{~s}$, and the wettability was measured at each temperature. Finally it was cooled to room temperature. When the measurements were done on the $\mathrm{TiO}_{2}$ nanowire structures Scanning Electron Microscopy (SEM) was used to observe the surface before and after the experiments.

The surface structure of graphite rings, new unused rings and after a number of castings, was observed by SEM, and the porosity of the mentioned graphite rings was compared. Also, the interface between a molten aluminum droplet and a graphite ring, after cooling to room temperature, was investigated. 


\section{Results}

In Figure 1a, the structure of $\mathrm{TiO}_{2}$ nanowires is shown. The diameter of the nanowires is about $50-200 \mathrm{~nm}$. The nanowires at the edge of the substrate is coarser than in the middle of it. The nanowires are grown in random orientations. Figure $1 b$, shows the structure after it has been in contact with a molten aluminum droplet.

a)

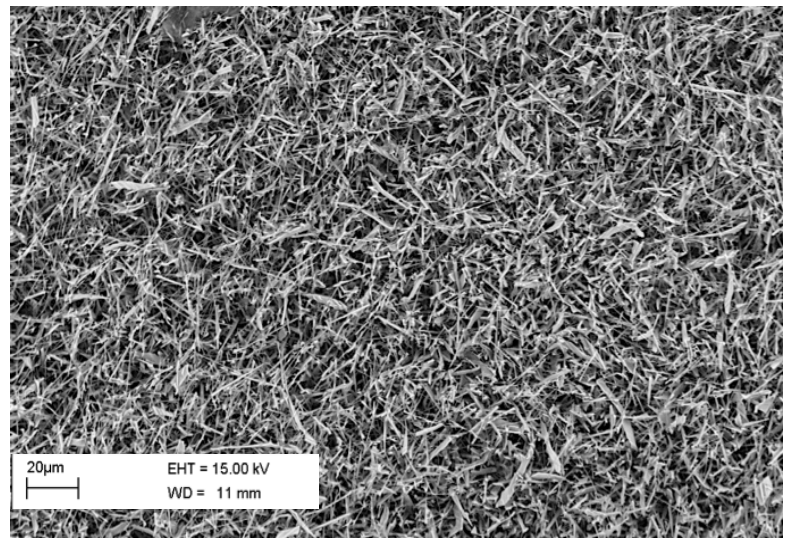

b)

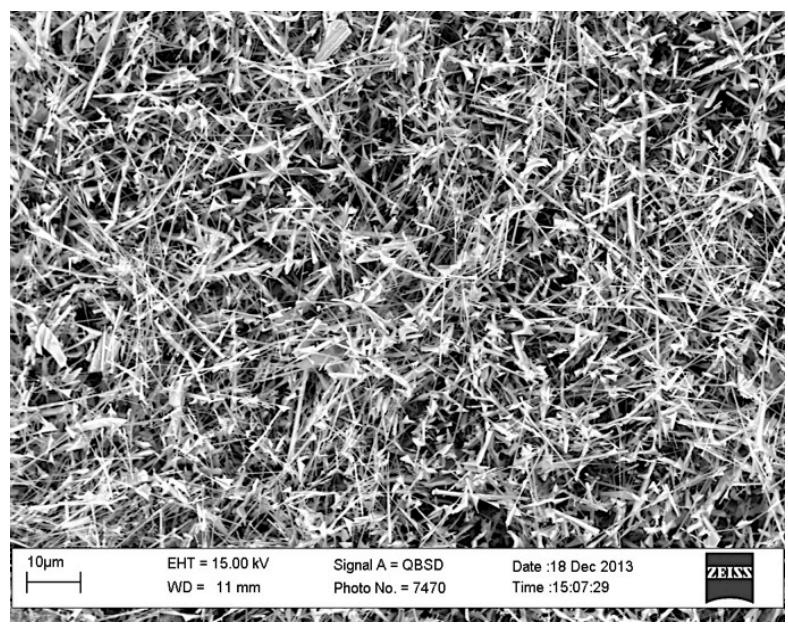

Figure 1: The $\mathrm{TiO}_{2}$ nanowires structure a) before; b) after interaction with molten aluminum.

The internal surface structures, i.e. the surfaces that are in contact with molten aluminum, of new and used graphite rings are shown in Figure 2. These structures show the porosity of each graphite ring before and after use. As it is obvious from Figures $2 \mathrm{a}$ and $\mathrm{b}$, the porosities of the graphite ring before casting are larger, and in some areas deeper, in comparison with the porosities of the graphite ring after a number of castings. It is estimated (image analysis by ImageJ) that the porosity of the graphite ring before casting is $20 \%$, and after casting reduced to $12 \%$. This shows that the contact with the molten aluminum influences the porous structure of the ring. a)

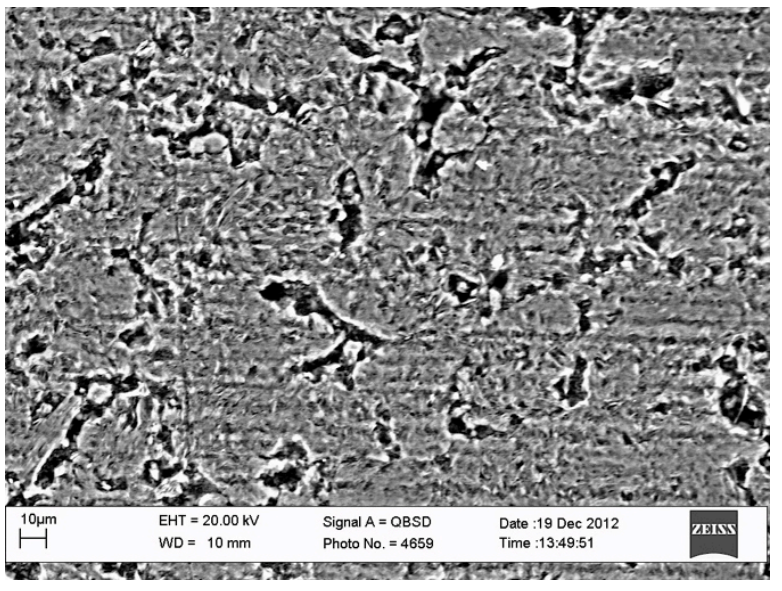

b)

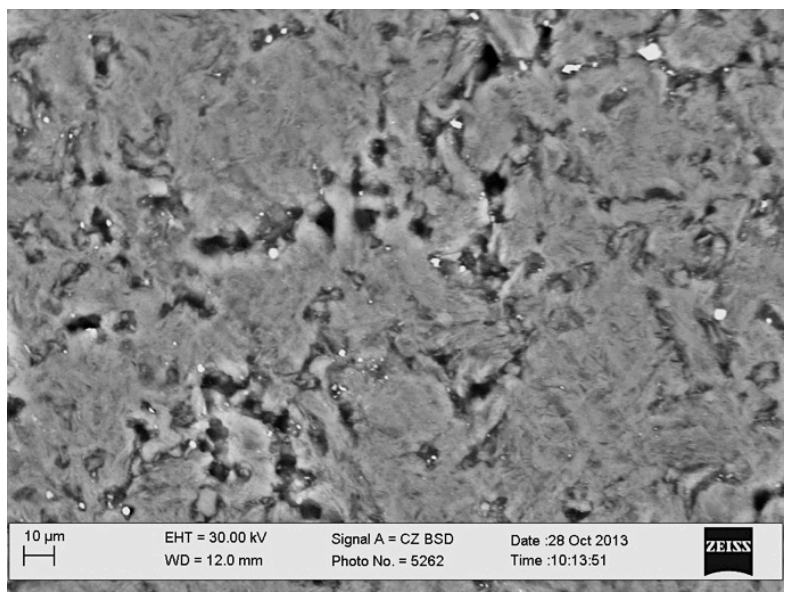

Figure 2: The graphite ring porous structure: a) new ring before casting; b) after a number of castings at end of life.

The contact angle measurements on a new graphite ring was done at different temperatures, from $800^{\circ} \mathrm{C}$ down to $650^{\circ} \mathrm{C}$. The results from the measurements are shown in Figure 3, and it can be seen that the contact angle doesn't change a lot by changing the temperature, or in other words, the contact angles remain approximately constant during cooling from $800^{\circ} \mathrm{C}$ down to $650^{\circ} \mathrm{C}$. At $800^{\circ} \mathrm{C}$ the contact angle was estimated to 133 degrees, and close to melting point $\left(660^{\circ} \mathrm{C}\right)$ is only decreased to about 127 degrees.

Figure $3 \mathrm{a}$ also shows, if the two curves are compared, that the contact angles remain approximately unchanged during the 30 s that is studied. It can e.g. be seen that the contact angle at $660^{\circ} \mathrm{C}$ goes from 127 to 126.5 degree during the 30 s holding time.

Figure $3 b$, illustrates the interface of graphite (dark area) and solid aluminum droplet (light area) after cooling to the room temperature. It is obvious from this figure that the molten aluminum penetrate and stick to the graphite ring after solidification. The measured contact angle after solidification of molten droplet is, however, still about 130 degree. It is clear that temperature changes do not influence the contact angles to any larger extent, as it differs by just a few degrees over the studied range, but figure $3 \mathrm{~b}$ anyway shows an interaction at the interface. 
a)

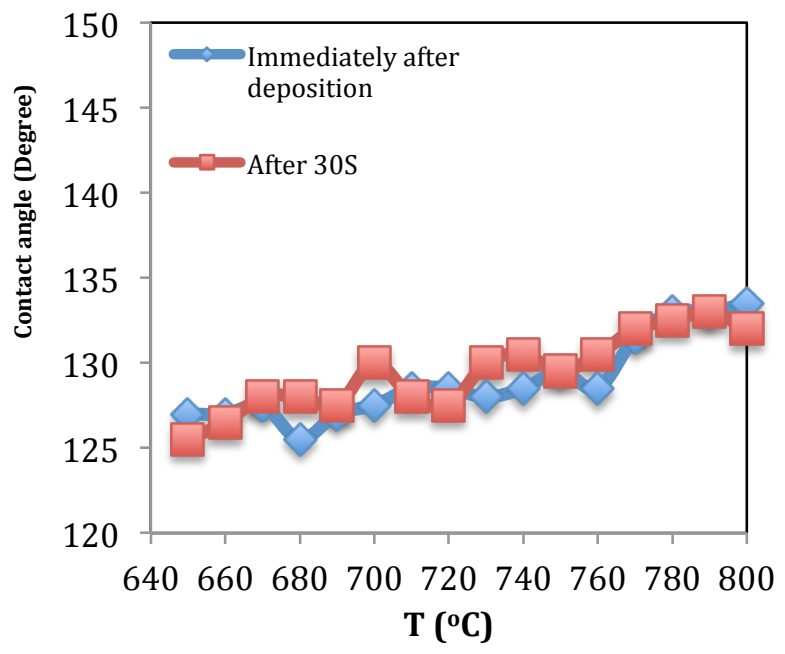

b)

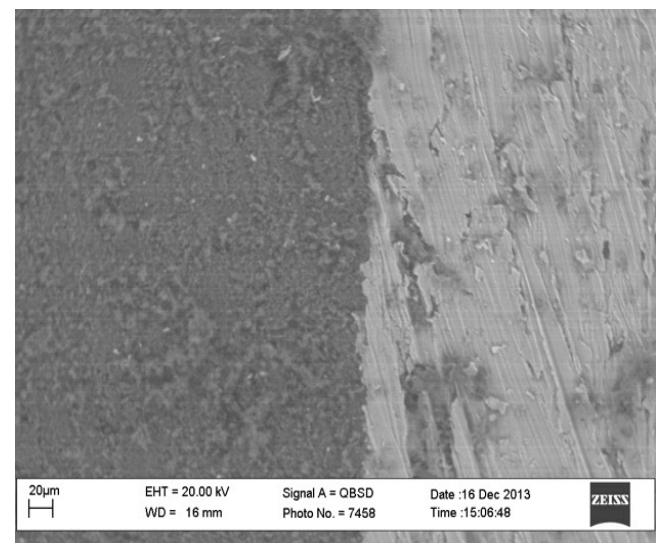

Figure 3: a) The contact angle measurement results of graphite ring by molten aluminum as a function of temperature, b) The graphite ring cross section after interaction with molten aluminum, showing graphite to the left and solidified aluminum to the right.

A molten aluminum droplet placed on a $\mathrm{TiO}_{2}$ nanowire structured surface at $700^{\circ} \mathrm{C}$ is shown in Figure 4 . As it is illustrated in this Figure, the aluminum droplet cannot attach to the $\mathrm{TiO}_{2}$ nanowires at all. The results were completely similar at higher and lower temperatures. As it is shown in Figure $1 \mathrm{a}$ and $\mathrm{b}$, it can be seen that the nanowire structure in both figures are the same and no mark of aluminum attachment to the nanostructures can be observed.

\section{Discussion}

The DC casting air-slip technique is a frictionless process due to airflow and lubricant between graphite ring and molten metal. The surface defects caused by increased friction to the inner side of the ring arise when some pores in certain areas of the graphite ring are clogged (Figure 2b). As it is mentioned above the porosity of a new graphite ring is about $20 \%$, and it decreases to about $12 \%$ after a number of castings. The porosity will be decreased due to polymerization and oil that is stuck to the pores after several casting. Figure 5 illustrates how the air flow through the ring decreases as the number of castings increase [14]. It can also be seen in the figure that the a)

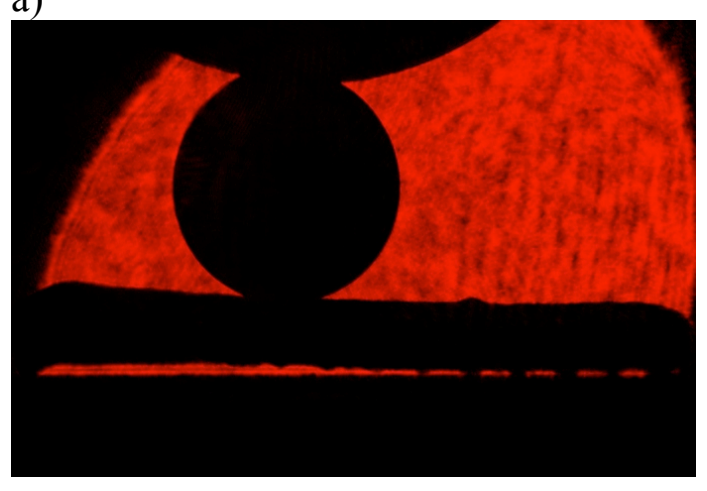

b)

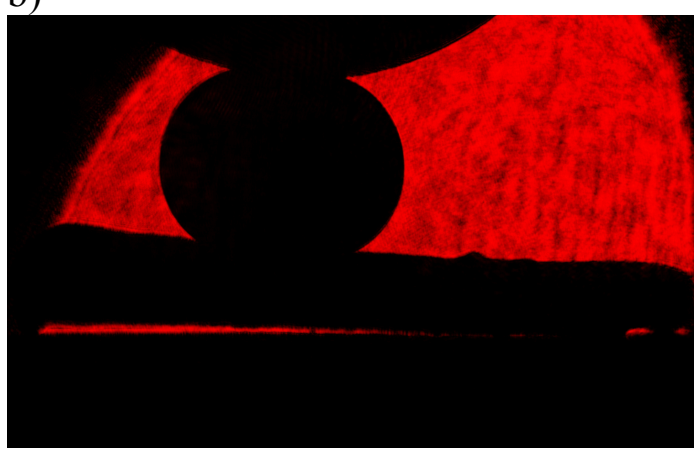

c)

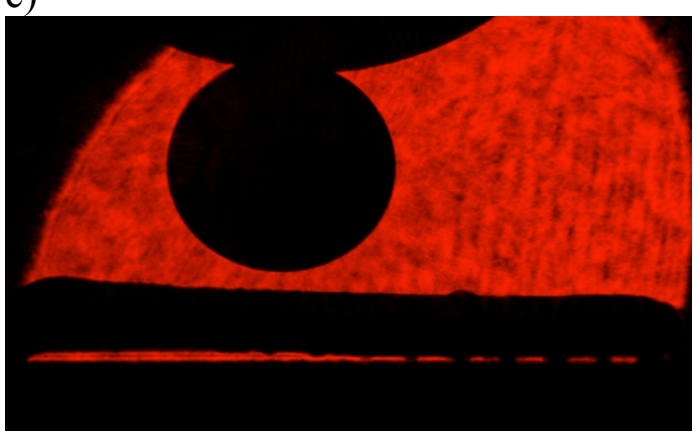

Figure 4: A molten aluminum droplet at $700^{\circ} \mathrm{C}$ a) The droplet is placed on the $\mathrm{TiO}_{2}$ nanowires substrate; b) The droplet is pressed against the substrate c) After detaching the dispenser tube [10] with the droplet, and still no trace of wetting on the surface.

flow can vary strongly around the circumference indicating critical points for defect formation, especially when the ring gets old and the flow at some spots approaches zero, e.g. at position 10 in the figure.

As a consequence of decreased mold porosity the ability to push away molten aluminum and/or a solid shell from the graphite ring will decrease. Therefore, the molten metal can contact the graphite ring and if wetting occurs scratches, or so-called vertical drags, are created on the billet surface. It is well known, in cast house operations, that the surface defects increase when the graphite ring gets old, but the mechanism behind it, is not clarified.

Points along the circumference where the flow is very low will give corresponding protrusions of the melt surface. The oxide skin, which always covers the surface [15], can break at such positions and as the wetting increasess for the free metal surface compared to the oxidized surface [8] the probability of contacting and sticking will be increased. When a contact between the molten metal and graphite is established it is not 
clear why the metal sticks to the graphite as the present results show relatively low wettability with a contact angle in the range of 126 to 133 , Figure 3a. However, the physical characteristics of the substrate surface e.g. micro cavities, i.e. the porosity in the ring surface, can influence and change the wettability [5], and as it is illustrated in Figure 3b, metal seems to have penetrated and probably reacted with the graphite ring. The reaction that can be expected between aluminum and graphite is the formation of $\mathrm{Al}_{4} \mathrm{C}_{3}$ crystals [9]. The present results have been obtained for pure aluminum, but for alloys, and especially magnesium containing alloys, the wettability can be expected to increase [4], as the magnesium weakens the oxide skin.

A way to avoid the wetting and thus the vertical drag defects would be by means to decrease the wetting probability. In the present paper the formation of a nanowire structure on the ring surface is discussed. Other possibilities could be to mechanically form a fine structure on the graphite ring surface by grinding or milling [16], but that has not been explored in this investigation.

Due to multiple applications, extensive research has been done to fabricate $\mathrm{TiO}_{2}$ nanowires. Many have developed the synthesis of $\mathrm{TiO}_{2}$ nanowires by membrane-based method (wet method). Also, some studies have been devoted to make $\mathrm{TiO}_{2}$ nanowires by dry methods (from vapor phase), but due to the high melting point and low vapor pressure of $\mathrm{TiO}_{2}$ such methods are limited [17-20].

Some of the dry methods are based on the synthesis of $\mathrm{TiO}_{2}$ nanowires by catalyst-assisted vapor-phase synthesis,

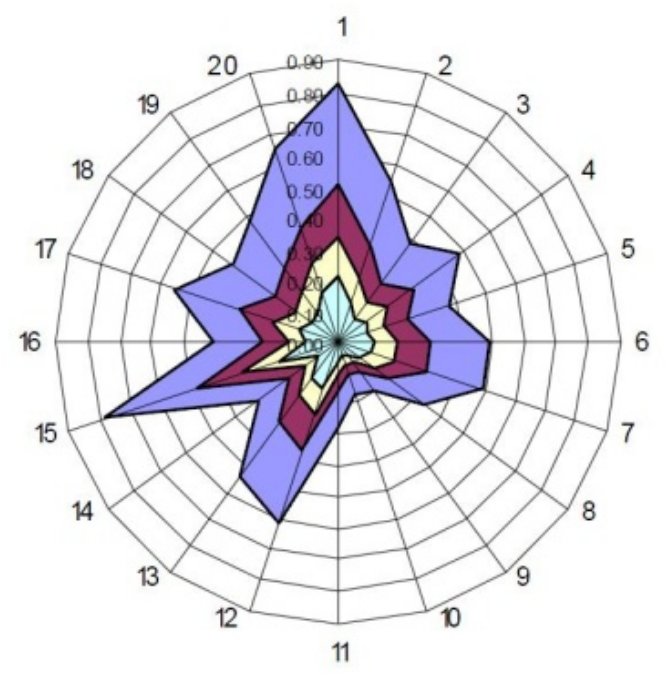

$\square$ New $\square 100$ casts $\square 200$ casts $\square 300$ casts

Figure 5: Diagram showing how air flow through a graphite ring, can be both inhomogeneous and decrease with the number of castings.

in which a $\mathrm{Ni}$ or $\mathrm{Au}$ thin layer is used as catalyst $[18,19,21]$.
In the method used in this paper, an Au layer was applied as a catalyst on a titanium substrate. The Au layers were melted during the synthesis and $\mathrm{TiO}_{2}$ nanowires were grown via the vapor-liquid-solid, VLS, mechanism [22]. The used technique would not be possible to apply for graphite rings at a larger scale as they decompose at the actual temperature and atmosphere, and it is also difficult to cover a large surface. However, recently a method to grow nanowires of GaAs on $\mathrm{Au}$ droplets in an aerosol has been developed [23, 24], and as it is clear from the present results that $\mathrm{TiO}_{2}$ nanowires grow by VLS mechanism on Au droplets the aerosol technique would be possible to apply. Nanoparticles, in the shape of short wires, can thus be deposited at a reasonable rate on any kind of substrate when they leave the growth chamber in an aerosol.

The wettability measurements clearly show that a droplet of molten aluminum cannot wet the $\mathrm{TiO}_{2}$ nanowire structure, Figure 4, which means the contact angle is $>>90^{\circ}$ and the droplet can be removed from the substrate without any damage to the structure, Figure 1.

However, it is reported [25] that planar $\mathrm{TiO}_{2}$ substrates can be wetted by and react with molten aluminum at temperatures above $1100^{\circ} \mathrm{C}$ [25-27], according to the following reaction [28]:

$\mathrm{TiO}_{2}+\mathrm{Al} \rightarrow \mathrm{Al}_{2} \mathrm{O}_{3}+\mathrm{Al}_{\mathrm{x}} \mathrm{Ti}_{\mathrm{y}}$

The mass balance of the reaction will be dependent on what AlTi compound is formed, where possible alternatives are $\mathrm{Al}_{3} \mathrm{Ti}, \mathrm{AlTi}$ or $\mathrm{AlTi}_{3}$. It is possible that oxygen from $\mathrm{TiO}_{2}$ nanowire tips can diffuse into the aluminum droplets as $\mathrm{O}^{-2}$ to form $\mathrm{Al}_{2} \mathrm{O}_{3}$ [26]. This oxide, in contact with a tip, may prevent the attachment of aluminum.

The wettability may be dependent on the chemical reaction also at lower temperatures, but anyway the nanowire structure studied here strongly enhances the de-wetting, and it is possible that nanowire structures of other materials and manufacturing methods might give similar effects. It is therefore probable that surface layers of nanostructures could be a possible solution to the problem of surface defects such as vertical drags on DC cast billets. It may also be possible to totally replace the porous graphite ring with rings of other suitable materials covered by nanostructures.

\section{Conclusions}

The interaction between a graphite ring, used in DC casting of aluminum alloys, and molten aluminum can cause serious problems such as vertical drag defect in billet production. The interaction and wetting behavior have been studied and compared to the melt interaction with a $\mathrm{TiO}_{2}$ nanowire structure. It was concluded that a strong de-wettability was obtained by the nanostructure, and it was proposed that a nanostructured surface coatings on casting rings can prevent the formation of VD defects.

\section{References}

[1] M. Ksiazek, N. Sobczak, B. Mikulowski, W. Radziwill, I. surowiak, Materials Science and Engineering: A, 324 (2002) 162-167. [2] Y. Yuan, T.R. Lee, Surface Science Techniques, Springer Series in Surface Sciences, 51 (2013) 3-34.

[3] V.H. López, A.R. Kennedy, Journal of Colloid and Interface Science, 298 (2006) 356-362.

[4] J. Hashim, L. Looney, M.S.J. Hashmi, Journal of Materials Processing Technology, 119 (2001) 324-328.
[5] N. Sobczak, M. Singh, R. Asthana, Current Opinion Solid State \& Materials Science 9(2006) 241-253.

[6] N. Sobczak, J. Sobczak, R. Asthana, R. Purgert, China Foundary, 7 (2010) 425-437.

[7] D. Kocaefe, G. Ergin, V. Villeneuve, Y. Kocaefe, Archives of Computational Materials Science and Surface Engineering, 1 (2009) 213-224.

[8] K. Landry, S. Kalogeropoulou, N. Eustathopoulos, Materials Science and Engineering: A, 254 (1998) 99-111. 
[9] B. Sarina, T. Kai, A. Kvithyld, T. Engh, M. Tangstad,

Transactions of Nonferrous Metals Society of China, 22 (2012) 19301938.

[10] L.y. Zhang, P. Shen, Y. Qi, Q.C. Jiang, Applied Surface Science, 276 (2013) 424-432.

[11] T. Carlberg, A.E.W. Jarfors, Metallurgical aand Materials Transactions B, 45 B (2013) 175-181.

[12] W. Barthlott, C. Neinhuis, Planta, 202 (1997) 1-8.

[13] P. Gould, Materials Today, 6 (2003) 44-48.

[14] M. Erdegren, Licentiate Thesis, Natural Sciences, Engineering and Mathematics, Mid Sweden University, Sundsvall, Sweden, 2012.

[15] N. Bayat, T. Carlberg, JOM, 66, No. 5 (2014) 700-710.

[16] T. Duffar, M.D. Serrano, L. Lerin, J.L. Santailler, Cryst. Res. Technol., 34 (1999) 457-469.

[17] M. Xia, Y. Wang, H. Li, Y. Zeng, B. Qu, F. Wang, A. Pan, B. Zou, Q. Zhang, Y. Wang, Materials Letters, 64 (2010) 2392-2394. [18] J.M. Wu, H.C. Shih, W.T. Wu, Y.K. Tseng, I.C. Chen, Crystal Growth, 281 (2005) 384-390.

[19] A.C. Dupuis, L. Jodin, E. Rouviere, Applied Surface Science, 253 (2006) 1227-12335.
[20] Y.D. Premchand, T. Djenizian, F. Vacandio, P. Knauth, Elecrochemistry Communications, 8 (2006) 1840-1844.

[21] J.M. Baik, M.H. Kim, C. Larson, X. Chen, S. Guo, A.M. Wodtke, M. Moskovits, APPLIED PHYSICS LETTERS, 92 (2008) 242111-242111-242111-242113.

[22] Y. xia, P. Yang, Y. Sun, Y. Wu, B. Mayers, B. Gates, Y. Yin, F. Kim, H. Yan, Advanced Materials, 15, No. 5 (2003) 353-389.

[23] M.H. Magnusson, K. Deppert, J.O. Malm, NanoStructured Materials, 12 (1999) 45-48.

[24] M. Heurlin, M.H. Magnusson, D. Lindgren, M. Ek, L.R.

Wallenberg, K. Depper, L. Samuelson, Nature, 492 (2012) 90-94.

[25] N. Sobczak, L. Stobierski, W. Radziwill, M. Ksiazek, M.

Warmuzek, Surface and Interface Analysis, 36 (2004) 1067-1070.

[26] J.J. Payyapilly, Materials Science and Engineering, Virginia Polytechnic Institute and State University, 2008, pp. 125.

[27] P. Shen, H. Fujii, K. Nogi, Acta Materialia, 54 (2006) 15591569.

[28] N. Sobczak, R. Asthana, W. Radziwi, R. Nowak, A. Kudyba, Archives of Metallurgy and Materials 52 (2007) 55-65. 